\title{
Effort Reward Imbalance for Psychological Morbidity among First Year Postgraduate Residents
}

\author{
Wei-Ching Chung ${ }^{1,2,5}$, Shu-Ching Yang ${ }^{2}$, Wen-Bin Chiou ${ }^{2}$ and Dong-Sheng Tzeng $3,4,5^{*}$ \\ ${ }^{1}$ Department of Nursing, Fooyin General Hospital, Pingtung, Taiwan \\ ${ }^{2}$ Graduate Institute of Education, National Sun Yat-Sen University, Taiwan \\ ${ }^{3}$ Department of Psychiatry, Kaohsiung Armed Forces Hospital, Kaohsiung, Taiwan \\ ${ }^{4}$ Institute of Undersea and Hyperbaric Medicine, National Defense Medical Center, Taiwan \\ ${ }^{5}$ School of Nursing, Fooyin University, Taiwan
}

*Corresponding author: Dong-Sheng Tzeng, No 2, Jung-Jeng 1st Rd., Kaohsiung City, Taiwan, Tel: 886-7-7490782; Fax: 886-77498706; E-mail: tzengds@hotmail.com

Received Date: November 20, 2014, Accepted Date: December 18, 2014, Published Date: December 27, 2014

Copyright: () 2015, Wei-Ching Chung et al., This is an open-access article distributed under the terms of the Creative Commons Attribution License, which permits unrestricted use, distribution, and reproduction in any medium, provided the original author and source are credited.

\begin{abstract}
Objective: Many studies have reported that the first postgraduate year (PGY-1) of residency training is marked by severe job stress. We want to investigate the mental health of PGY1 residents and to explore its relationship among job stress and personality.

Methods: Ninety-two PGY1 residents training at a regional teaching hospital in southern Taiwan were enrolled. The questionnaires used were tested and included the: Effort Reward Imbalance Questionnaire, Eysenck Personality Questionnaire, and Chinese version of the General Health Questionnaire, before and after participating in the psychiatry training program. The relationship between job stress, personality and psychological morbidity was tested using the generalized estimating equation-I.
\end{abstract}

Results: Fifty-six residents completed the follow up study. There were $23.2 \%(13 / 56)$ of the residents found to have psychological morbidity. There were no significant differences with regard to gender, age, and general data between two groups with or without psychological morbidity. The psychological morbidity was associated with neuroticism $(B=0.04, p=0.008)$; and associate with effort reward imbalance $(B=1.07, p=0.012)$.

Conclusions: This follow up study showed the neuroticism and effort reward imbalance might be closely related to psychological morbidity of PGY1. In designing educational program for PGY, it needs to concern the individual personality factor and job stress dimensions.

Keywords: Follow up study; Job stress; Neuroticism; First postgraduate year; Psychological morbidity

\section{Introduction}

In teaching hospitals, the relative factors about practice and training performance are important issues in educational policy. Due to the toll on physical strength, the doctors' health might be affected as well as their learning capacity and quality of patient care responsibilities $[1,2]$. According to previous investigations, excessive pressure derives mainly from work that can easily cause physical dysfunction [3]. With regard to mental function, the response to pressure might cause anxiety, depression, impatient or indifference behavior, poor memory, attention deficits, which can cause making strategic decisions difficult, overreaction to excessive criticism, poor problem solving and loss of originality, sleep problems and substance abuse such as cigarette and alcohol use $[4,5]$.

Compared to the general society in which psychological morbidity is reported to be between $9 \%$ and $24 \%$ in males and between $21 \%$ and $33.3 \%$ in women, psychological morbidity is more common among physicians $(27$ to $52 \%)[6,7]$. In a previous report, by this group, it was around $28 \%$, with younger subjects having a higher prevalence [5]. In a cross sectional study, job stress and work hours explained $24.7 \%$ of the variance in subjects with burnout; in addition, personality and coping strategies explained an additional $10.4 \%$ and $5.4 \%$ of the variance, respectively. The reasons for the poor health outcomes in physicians are of critical importance; especially for the first-year postgraduate residents (PGY1) [8].

Few studies have investigated personality and the variables associated with medical school with regard to work stress and health after graduation [9]. It is of great importance to investigate these factors because this information may be used in the recruitment/ admittance process of medical schools, and possibly to improve medical education [10]. Physicians show an increased prevalence of mental health problems, with the first postgraduate year being particularly stressful. Many predictors of mental health problems in medical school have included: previous mental health problems; not being married/cohabitant; the personality traits 'vulnerability' (or neuroticism); perceived stress, and lack of perceived diagnostic skills [11-13]. In comparison of measurement instruments on job strain, one study showed the decision-making authority [14], one in social support [15], the reasons of subscale and secular change show the associations between job strain on overcommitment and reward remained significant after eight years follow-up [16]. The aims of this 
Page 2 of 7

study were to investigate the psychological morbidity of PGY-1 residents and explore its relationship among job stress by effort reward imbalance and personality using a follow up study design at a regional teaching hospital in southern Taiwan.

\section{Methods}

The training course of the PGY-1 residents had been carried out at the medical college, scheduled as a month at the six affiliated teaching hospitals. The PGY1 psychiatry program involves one month of training in community medical science, to foster the attitude, and responsibility of assisting patients, as they recover, to return to the community. The concrete plans during the first week focus on orientation (including a brief introduction to psychiatry); the second week focused on the community rehabilitation center (including understanding the condition of the patient and occupational therapy, and farm shelters); the third week focused on community service (including on-the-spot investigation in the community, home care conferences and visits); the fourth week focused on visiting the network hospital, visiting and understanding the network hospital connection [17]. In this study, we used a follow up study design and repeated measurement to test the causal relationship of psychological morbidity from individual or environmental reasons. The Institution Review Board of the regional teaching hospital approved this study, the informed consent from the volunteering PGY1 residents was obtained to collect basic information; the data were kept confidential by following the Helsinki principle. The subjects filled out a series of questionnaires: Eysenck personality questionnaire (EPQ), general health questionnaire Chinese version (CHQ) and the effort reward imbalance questionnaire (ERIQ) on the first day. One month later, they filled out the CHQ once again; this was done in order to determine the correlation of individual variance such as gender, age, educational level, religion, marriage, life events (such as death of a relative, economic stress, marital or divorce event, sentinel events, and malpractice problems with legal implications), medical illness (such as diabetes and hypertension and/or other history of chronic disease), personality, and/or job stress with psychological morbidity in the PGY1 residents.

\section{Participants}

The participants were 92 PGY1 residents, from two regional teaching hospitals and four medical centers in southern Taiwan that focused on the field of community medical science, from January 2007 to December 2008. Fifty-six residents were recruited after signed the inform consent and finished the follow up study. There were 15 female and 41 male residents included in the study. The age range was from 26 to 32 years of age. There were $23.2 \%$ (13/56) of the residents found to have psychological morbidity based on the two surveys. In the first survey, 13 residents had psychological morbidity. In the repeated measurement of the CHQ, 9 residents reported improvement during the PGY1 training course, while 8 residents had worsening of their condition; two residents had persistent symptoms. Therefore, $17.9 \%$ (10/56) had psychological morbidity. Thirty-two residents came from another hospital, and 24 from our regional teaching hospital. Twentyfive residents will fix in internal medicine, 12 in surgery department, others in pediatrics, orthopedics and so on. Most of the residents were single.

\section{Instruments}

The personal data included gender, age, job category, educational level, marital status, smoking history, alcohol consumption history, history of hypnotic drug use, and life events over the past six months. The definition of life events included the death of a relative, economic stress, marital or divorce event, sentinel events, and malpractice problems with legal implications. The survey instruments used were the: Eysenk Personality Questionnaire (EPQ), Chinese version of General Health Questionnaire (CHQ) and the Effort Reward Imbalance Questionnaire (ERIQ).

\section{Chinese version of General Health Questionnaire (CHQ)}

The General Health Questionnaire-12 (Chinese Version) (CHQ) is a self-administered screening instrument used to assess psychological morbidity and minor psychiatric disorders. In the Chinese version of this instrument, two culturally relevant items have been added: a Chinese interpretation of anxiety ("huoqi") and somatic pain. The four answer choices for each CHQ item were assigned either a score of 0 or 1. "Not at all" and "About as usual" were assigned a score of 0 , and "more than usual" and "always" a score of 1. Psychopathology was considered based on the total score of all 12 questions. The participants were subdivided into potential cases $(>=3)$ and noncases $(<=2)$. This optimum cutoff point provides the best compromise between high sensitivity and a low false-positive rate, based on the Receiver Operating Characteristic curves, with a Cronbach`s alpha of $0.79[18]$.

\section{Eysenck Personality Questionnaire (EPQ)}

The EPQ was developed theoretically based on personality traits [19]; the Chinese version was developed by $\mathrm{Lu}$, in 1994. The EPQ is composed of two major personality traits, extraversion and neuroticism [20,21], with 14 and 11 items each. Higher scores tend to reveal higher levels of extraversion and neuroticism. Those that are extraverted are more sociable and impulsive, and those that are neurotic are more anxious and emotional [21].The Chinese version demonstrated a high internal consistency of 0.90 , with an internal consistency of 0.83 for the extraversion dimension and 0.80 for the neuroticism dimension which is the most widespread valid and reliable instrument in Taiwan. This study also found a high internal consistency of Chronbach's alpha of 0.87 for the extraversion dimension and 0.90 for the neuroticism dimension [22].

\section{Effort Reward Imbalance Questionnaire (ERIQ)}

The 23 item ERIQ consisted of three categories: "effort" (6 items), "reward" (11 items, including esteem, job promotion, and job security), and "overcommitment" (6 items). Responses to the items of "effort" and "reward" were scored on a fivepoint scale, 1 indicating no particularly stressful experience and 5 indicating a very highly stressful experience. The Cronbach alpha coefficients for "effort", "reward", and "overcommitment" for men were: $0.80,0.82$, and 0.66 , respectively and for women, $0.83,0.80$ and 0.66 [23]. According to a predefined algorithm, the ratio between the two categories of "effort" and "reward" (weighted by item numbers) was calculated to quantify the degree of mismatch between high cost and low gain [24]. "Effort" and "reward" were coded as dichotomous variables using the median of the total sample as the cutoff point $[24,25]$. Similarly, a positive effortreward 
Citation: Chung WC, Yang SC, Chiou WB, Tzeng DS (2015) Effort Reward Imbalance for Psychological Morbidity among First Year Postgraduate Residents. J Psychiatry 18: 223. doi:10.4172/2378-5756.1000223

Page 3 of 7

imbalance was defined by both high effort and low reward; a negative effortreward imbalance was defined by only high effort or low reward as well as by neither high effort nor low reward. A high effortreward ratio (ER ratio) and overcommitment were defined as falling within the upper tertile of the total distribution $[16,25]$.

\section{Data Analysis}

The chi-square test, student $\mathrm{t}$ test were used to examine the differences in the demographic variables between the two groups with or without psychological morbidity. The generalized estimating equation analysis was used to assess the relationships among gender, age, effort, reward, and personality factors to psychological morbidity.
A p-value $<0.05$ was considered significant. All statistical operations were performed using the SPSS 15.0 for Windows software package (SPSS, Chicago, IL., USA).

\section{Results}

The on duty days of residents decreased from 8 to 7 days per month. The average working hour is around 70 hours per week. There were no significant differences with regard to: gender, age, alcohol use, use of hypnotics, medical illness or life events and demographic data $(p>0.05)$ between the two groups with and without psychological morbidity (Table 1). The total score of the first CHQ survey was $0.9 \pm$ 1.4 and for the second survey it was $1.6 \pm 3.0(\mathrm{p}=0.03)$.

\begin{tabular}{|c|c|c|c|c|}
\hline & Psychological morbidity & & & \\
\hline & Cases 13 & Non 43 & $t / \times 2 / F$ & Sig. \\
\hline Gender & & & 1.18 & 0.278 \\
\hline male & 8 & 33 & & \\
\hline female & 5 & 10 & & \\
\hline Age & $28.2 \pm 2.8$ & $28.2 \pm 2.5$ & 0.01 & 0.997 \\
\hline Belong & & & 1.01 & 0.315 \\
\hline RTH & 4 & 20 & & \\
\hline others & 9 & 23 & & \\
\hline Department & & & 4.37 & 0.112 \\
\hline Internal medicine & 9 & 16 & & \\
\hline surgery & 1 & 11 & & \\
\hline others & 3 & 16 & & \\
\hline Marriage & & & 0.07 & 0.791 \\
\hline single & 11 & 35 & & \\
\hline married & 2 & 8 & & \\
\hline Smoking & & & 1.12 & 0.572 \\
\hline yes & 1 & 1 & & \\
\hline no & 12 & 42 & & \\
\hline Alcohol use & & & 1.30 & 0.254 \\
\hline yes & 0 & 4 & & \\
\hline no & 13 & 39 & & \\
\hline Hypnotics & & & 1.53 & 0.217 \\
\hline yes & 2 & 1 & & \\
\hline no & 11 & 42 & & \\
\hline Medical illness & & & 0.97 & 0.641 \\
\hline yes & 5 & 10 & & \\
\hline no & 8 & 33 & & \\
\hline
\end{tabular}


Citation: Chung WC, Yang SC, Chiou WB, Tzeng DS (2015) Effort Reward Imbalance for Psychological Morbidity among First Year

Page 4 of 7

\begin{tabular}{|l|l|l|l|l|}
\hline Life events & & & & \\
\hline yes & 2 & 2 & & \\
\hline no & 11 & 41 & & \\
\hline
\end{tabular}

Table 1: Demographic data of first-year postgraduate residents with and without psychological morbidity, at a regional teaching hospital in southern Taiwan, RTHabbreviation of regional teaching hospital; student t, Chi-square and ANOVA were used to test between groups.

The comparison of extraversion $(5.33 \pm 3.94,5.74 \pm 3.85, \mathrm{p}=0.751), \quad$ overcommitment $(18.38 \pm 2.99,16.26 \pm 2.62, \mathrm{p}=0.016)$, between the neuroticism $(6.31 \pm 1.84,3.58 \pm 3.01, \mathrm{p}=0.003)$, effort $(38.77 \pm 6.35$, two groups with and without psychological morbidity, which showed $34.74 \pm 6.49, \mathrm{p}=0.054)$, reward $(27.62 \pm 3.99,28.84 \pm 3.72, \mathrm{p}=0.311)$, higher neuroticism, ERI and overcommitment scores on the group effort-reward imbalance $(0.71 \pm 0.13,0.61 \pm 0.13, \mathrm{p}=0.019)$ and with psychological morbidity (Table 2$)$.

\begin{tabular}{|l|l|l|l|l|}
\hline & $\begin{array}{l}\text { Psychological morbidity } \\
\mathbf{N}=\mathbf{1 3}\end{array}$ & $\begin{array}{l}\text { Non-cases } \\
\mathbf{N}=\mathbf{4 3}\end{array}$ & $\mathbf{t}$ & Sig. \\
\hline Extraversion & $5.33 \pm 3.94$ & $5.74 \pm 3.85$ & 0.32 & 0.751 \\
\hline Neuroticism & $6.31 \pm 1.84$ & $3.58 \pm 3.01$ & -3.09 & 0.003 \\
\hline Effort & $38.77 \pm 6.35$ & $34.74 \pm 6.49$ & -1.97 & 0.054 \\
\hline Reward & $27.62 \pm 3.99$ & $28.84 \pm 3.72$ & 1.02 & 0.311 \\
\hline ERI & $0.71 \pm 0.13$ & $0.61 \pm 0.13$ & -2.43 & 0.019 \\
\hline Overcommitment & $18.38 \pm 2.99$ & $16.26 \pm 2.62$ & -2.49 & 0.016 \\
\hline
\end{tabular}

Table 2: The data from the Effort Reward Imbalance Questionnaire, Eysenck Personality Questionnaire, and Chinese version of the General Health Questionnaire of PGY-1 residents before a psychiatry training program. ERI: effort imbalance ratio Student t test was test between cases with non-cases.

\begin{tabular}{|l|l|l|l|l|l|l|}
\hline & & $95 \%$ Confidence Interval & & & & \\
\hline Parameter & B & S.E. & Lower & Upper & Wald Chi-Square & Sig. \\
\hline Intercept & -0.46 & 0.24 & -0.93 & 0.02 & 3.48 & 0.062 \\
\hline Male & -0.17 & 0.12 & -0.40 & 0.06 & 2.14 & 0.144 \\
\hline Female & $0 \mathrm{a}$ & & -0.03 & 0.01 & 0.56 & 0.456 \\
\hline Extraversion & -0.01 & 0.01 & 0.01 & 0.07 & 7.08 & 0.008 \\
\hline Neuroticism & 0.04 & 0.02 & 0.24 & 1.90 & 6.37 & 0.012 \\
\hline ERI & 1.07 & 0.42 & & & \\
\hline
\end{tabular}

Table 3: The psychological morbidity of PGY residents analyzed with job stress and personality by the generalized estimating equation-I, Department variable: psychological morbidity of base survey and follow up , Method: parsimonious model of (intercept), gender, extraversion, neuroticism, and ERI analyzed by GEE. a: set to zero because this parameter is redundant.

When the dependent variable was set as the pre and after CHQ tests, the unstructured working correlation matrix method with factors such as gender, age, alcohol, smoking, life events, covariates such as extraversion, neuroticism, effort and reward were used in the method of estimation (Table 3). In parsimonious model under repeated measurement of generalized estimated equation, the neuroticism was associated with psychological morbidity $(B=0.04, p=0.008)$; the ERI associated with psychological morbidity too $(B=1.07, p=0.012)$.

\section{Discussion}

The results of this study showed that the resident's personality and job stress were closely related to their general health. The reasons of above might be due to firstly, the outcome variable is the nature of mental health which more correlated with personality; secondly, the well structural training course and payment system of PGY are constant which made the individual effort and reward less variable. No matter how, in assessing psychological morbidity, the personal characteristic and job stress, especially for female resident, were important factors. The prevalence of psychological morbidity for all 
participating PGY-1 residents of this study was $23.2 \%$, higher in female physicians (33.3\%). In a previous report it was around 28\% [5], which is consistent with the current results. The lower frequency of alcohol, smoking and hypnotic drug use in the subjects reported here with psychological morbidity might be a result of gender and department differences which affect the distribution of the substance use frequency. Therefore, this study presents a demographic picture different from other reports $[6,12,13,15]$.

Psychiatry training is thought to be easier than other specialties; due to the shorter working hours and on call days. The definition of a case was the total score of the CHQ 3; the mean result of the total score of the first CHQ survey was lower than the second survey. The fewer on call days was not reflected in a better total CHQ score in this follow up study. This might have been due to in the fact that for the community support program, of the regional teaching hospital, had to join the community service program in the day time; the PGY1 residents had to finish their charting of patient records in the acute ward during the night, which increased the number of working hours. Another possible reason might be that the regional teaching hospital is the only open model integrative delivery system in Taiwan, which includes the high tension and work loading on duty of risky assessments in care quality for acute mental disorder patients which are unanticipated as PGY1's choice [17]. The other reason might be due to the uncertainty of questionnaire, people with a score of 3 , exceeding the cut-off level, have a $50 \%$ probability of being a case; the probability highly rises with increasing scores [26]. In our previous study, we found the secular changes in perceptions of job strain to be significantly associated with psychological morbidity in our study population working in a changing work environment [16].In the future, the investigation of different characteristics among different specialties using the electronic time clock system instead of a self-report system during working hours might improve the accuracy of the information collected.

Job stress, assessed by the ERIQ in various working environments, in different countries, has been widely reported. However, application of this model to physicians has been relatively rare. The PGY-1 residents have constant and increasing extrinsic and intrinsic stress with a negative impact on health and life satisfaction. In ERI model [27], there is explicit emphasis on individual attributes, particularly coping characteristics of high intrinsic effort, which is defined by the concept of "need for control". The extrinsic efforts, defined by a high workload, are also specified. This model also takes three different sources of reward into account: financial, esteem, and occupational social status control (i.e., promotion prospects and job security). Variables measuring low reward in terms of low status control in relation to high extrinsic effort or intrinsic effort have been shown to independently predict new cardiovascular events in a prospective study [28-30]. ERI and overcommitment have been identified as biological correlates of salivary cortisol and higher blood pressure [31]. ERI has also been linked to other outcomes including sick leave [32], alcohol dependence [33], psychological wellbeing [34], burnout, and job satisfaction [35,36]. In this study, for the PGY1 physician job category; the ERI and overcommitment might be valid factors to assess the relationship of psychological morbidity with job stress in student- $t$ test, but overcommitment did not touch the effect in the regression analysis which might be due to ERI interact with overcommitment. The other reason might be due to the overcommitment is professional culture and habit in physicians. These associations based on one baseline estimate of job strain may not be accurate because they fail to take into account changes in perceptions of that factor over time $[15,16]$.

The results of this study showed that overcommitment might be a good predictor of psychological morbidity for both genders. The other studies were better for men than women which might be due to the gender distribution in the study sample [31,37] Overcommitment at work has been associated with psychological morbidity in several studies $[6,16,38-40]$. The ERI was used in this study, a psychometrically accepted measure of work-related stress and overcommitment grounded in sociological theory [24] Overcommitment is an independent concept because it stems from intrinsic effort/need for control and approval [41] and the inability to withdraw from work [42] In this study, high overcommitment revealed significantly higher psychological morbidity; however, the results were not significant when the analysis was performed with effort and reward. The reason might be the selection bias in the choice of PGY1 where psychiatry teaching run could not show the change in effort reward imbalance. The other reason might be in the characteristic of physician which needs general long duty days and working hours during the training period.

In this study, neuroticism was a good predictor to psychological morbidity. Neuroticism predicted a more negative effect on aversive and threat cues, and the aversive pictures/recovery period [13]. One reported PGY who exhibited less neuroticism, more conscientiousness and a propensity for positive affectivity, as well as a tendency to use engagement coping strategies [8]. In facing aversive events and high job stress, as with PGY-1 residents, neuroticism predicts affective responses and inverse affective recovery successfully. In this study, we found significant difference of the neuroticism and overcommitment between the case and control group. There were few published papers on investigating these two factors simultaneously in scientific field. We hypothesize the neuroticism interact to the inability withdraw from work as overcommitment [24], resulting in continued exaggerated efforts combined with disappointing rewards, might also increase the risk of poor health. In the future, we need larger sample size and follow up study to explore the role of neuroticism and overcommitment $[6,16]$

\section{Limitations}

The limitations of this study include the following. The small sample size does not represent all residents including those of other hospitals, ethnicities and from other countries. The different training locations of cluster might confound the main interesting. But repeated measurement would increase the longitudinal data sets by twofold from 56 to 112 data sets which might reduce the reporting bias even GEE is a method of estimation and the standard error of parameter might be underestimated. The fact that the subjects came from six different hospitals would be better because the inherent personality profile associated with PGY1 that is associated with their choice of specialty. Another limitation is the psychiatry course of one month was a short observation time; long term effects even with the follow up design might not be predicted from such a short-term study. A prepost questioning at the beginning and the end of the PGY-1 would be the right method. However, the examination was held in the period of the PGY-1 psychiatry program which is not as stressful as the other specialties, especially for residents who would like to specialize in internal medicine, like most of them wanted to. 


\section{Conclusion}

This follow up study showed the neuroticism and effort reward imbalance might be closely related to psychological morbidity of PGY1. In designing educational program for PGY, it needs to concern the individual personality factor and job stress dimension.

\section{Acknowledgements}

Disclosure statement that all authors explicitly declares there are not any conflicts of interest.

\section{Implications for Academic Leaders} PGY1.

The neuroticism was closely related to psychological morbidity of

The effort reward imbalance in job stress was closely related to their general health.

In designing educational program for PGY, it needs to concern the individual personality factor and job stress dimension.

\section{References}

1. West CP, Tan AD, Habermann TM, Sloan JA, Shenafelt TD (2009) Association of resident fatigue and distress with perceived medical errors. JAMA 302: 1294-1300.

2. Shanafelt TD, Balch CM, Bechamps G, Russell T, Dyrbye T, et al. (2010) Burnout and medical errors among American surgeons. Ann Surg 51: 995-1000.

3. Michie S (2002) Cause and management of stress at work. Occup Environ Med59: 67-72.

4. Dyrbye LN, Thomas MR, Shanafelt TD (2006) Systematic review of depression, anxiety, and other indicators of psychological distress among U.S. and Canadian medical students. Acad Med 81: 354-373.

5. Tzeng DS, Yang CY, Chung WC, Fan PL, Lung FW (2009) Psychological Morbidity, Quality of Life and their Correlations among Military Health Care Workers in Taiwan. Ind Health 47: 626-634.

6. Tzeng DS, Chung WC, Lin CH, Yang CY (2012) Effort reward imbalance and quality of life of healthcare workers in military hospitals: a crosssectional study. BMC Health Services Research 12: 309.

7. Rona RJ, Hooper R. Greenberg N, Jones M, Wessely S (2006) Medical downgrading, self-perception of health, and psychological symptoms in the British Armed Forces. Occup Environ Med 63: 250-254.

8. Lue BH, Chen HJ, Wang CW, Cheng Y, Chen MC (2010) Stress, personal characteristics and burnout among first postgraduate year residents: a nationwide study in Taiwan. Med Teach 32: 400-407.

9. Buddeberg-Fischer B, Klaghofer R, Stamm M, Siegrist J, Buddeberg C (2008) Work stress and reduced health in young physicians: prospective evidence from Swiss residents. Int Arch Occup Environ Health 82: 31-38.

10. Finset KB, Gude T, Hem E, Tyssen R, Ekeberg O, Vaglum P (2005) Which young physicians are satisfied with their work? A prospective nationwide study in Norway. BMC Med Edu 5: 19.

11. Tyssen R, Vaglum P, Grønvold NT, Ekeberg O (2001) Factors in medical school that predict postgraduate mental health problems in need of treatment. A nationwide and longitudinal study. Med Edu 35: 110-20.

12. Tyssen R, Vaglum P (2002) Mental health problems among young doctors: an updated review of prospective studies 10: 154-165.

13. Sen S, Kranzler HR, Krysta 1JH, Speller H, Chan G, et al. (2010) A Prospective Cohort Study Investigating Factors Associated With Depression During Medical Internship. Arch Gen Psychiatry 67: 557-565.
14. Tsai YC, Liu CH (2012) Factors and symptoms associated with work stress and health-promoting lifestyles among hospital staff: a pilot study in Taiwan. BMC Health Serv Res16 12: 199.

15. Tzeng DS, Chung WC, Fan PL, Lung FW, Yang CY (2013) The Effect of Changes in Job Strain on Psychological Morbidity and Quality of Life in Military Hospital Nurses in Taiwan: A Follow-up Study. Ind Health 51: 443-451.

16. Sembajwe G, Wahrendorf M, Siegris J, Sitta R, Zins M, et al. (2012) Effects of job strain on fatigue: cross-sectional and prospective views of the job content questionnaire and effort--reward imbalance in the GAZEL cohort. Occup Environ Med 69: 377-384.

17. Tzeng DS, Lian LC, Chang CU, Yang CY, Lee GT, et al. (2007) Healthcare in schizophrenia: effectiveness and progress of a redesigned care network. BMC Health Serv Res 7: 129.

18. Cheng TA, Williams P (1986) The design and development of a screening questionnaire (CHQ for use in community studies of mental disorders in Taiwan. Psychol Med16: 415-422.

19. Eysenck H J, Eysenck SBG (1975) Manual for the Eysenck Personality Questionnaire. London: Hodder \& Stoughton.

20. Depue RA, Collins PF (1999) Neurobiology of the structure of personality: Dopamine, incentive motivation and extraversion. The Behavioral and Brain Sciences 22: 491-569.

21. Plomin R, DeFries JC, McClean GE, McGuffin P (2001) Personality and personality disorders: In Behavioral genetics. New York: Worth 234-257.

22. Lu L (1994) University transition. Major and minor life stressors, personality characteristics and mental health. Psychology Medicine 24: 81-87.

23. Tseng HP, Cheng Y (2002) Reliability and validity of the Chinese demand control support model and effort reward imbalance model questionnaires: A study among employees of the microelectronic industry. Taiwan Journal of Public Health 21: 420-432. [in Chinese with English abstract].

24. Siegrist J, Starke D, Chandola T, Godin I, Marmot M, et al. (2004) The measurement of effort-reward imbalance at work: European comparisons. Soc Sci Med 58: 1483-1499.

25. Niedhammer I, Tek ML, Starke D, Siegrist J (2004) Effort reward imbalance model and self-reported health: Crosssectional and prospective findings from the GAZEL cohort. Soc Sci Med 58: 1531-1541.

26. Goldberg D (1972) The Detection of Psychiatric Illness by Questionnaire. London: Oxford University Press.

27. Siegrist J (1998) Adverse health effects of effort reward imbalance at work: Theory, empirical support, and implications for prevention. In Cooper CL, editor. Theories of Organizational Stress. Oxford University Press 190-204.

28. Siegrist J (1996) Adverse health effects of high-effort/low-reward conditions. J Occup Health Psychol 1: 27-41.

29. Bosma H, Peter R, Siegrist J, Marmot M (1998) Two alternative job stress models and the risk of coronary heart disease. Am J Public Health 88: 68-74.

30. Kuper H, Singh-Manoux A, Siegrist J, Marmot M (2002) When reciprocity fails: Effort reward imbalance in relation to coronary heart disease and health functioning within the Whitehall II study. Occup Environ Med 59: 777-784.

31. Steptoe A, Wardle J, Marmot M (2004) Positive affect and health-related neuroendocrine, cardiovascular, and inflammatory processes. PNAS.

32. Peter R, Siegrist J (1997) Chronic work stress, sickness absence, and hypertension in middle managers: General or specific sociological explanations? Soc Sci Med 45: 1111-1120.

33. Head J, Stansfeld SA, Siegrist J (2004) The psychosocial work environment and alcohol dependence: A prospective study. Occup Environ Med 61: 219-224.

34. de Jonge J, Bosma H, Peter R, Siegrist J (2000) Job strain, effort-reward imbalance and employee well-being: A large-scale cross-sectional study. Soc Sci Med 50: 1317-1327. 
Citation: Chung WC, Yang SC, Chiou WB, Tzeng DS (2015) Effort Reward Imbalance for Psychological Morbidity among First Year Postgraduate Residents. J Psychiatry 18: 223. doi:10.4172/2378-5756.1000223

Page 7 of 7

35. Bakker AB, Killmer CH, Siegrist J, Schaufeli WB (2000) Effort-reward imbalance and burnout among nurses. J Adv Nurs 31: 884-891.

36. Lewig KA, Dollard MF (2003) Emotional dissonance, emotional exhaustion and job satisfaction in call center workers. European Journal of Work \& Organizational Psychology 12: 366-392.

37. Van Vegchel N, de Jonge J, Landsbergis PA (2005) Occupational stress in (inter)action: the interplay between job demands and job resources. J Organiz Behav 26: 535-560.

38. Niedhammer I, Chastang JF, David S, Barouhiel L, Barrandon G (2006) Psychosocial work environment and mental health: Job-strain and effortreward imbalance models in a context of major organizational changes. Int J Occup Environ Health 12: 111-119.

39. Pikhart H, Bobak M, Pajak A, Malyutina S, Kubinova R, et al. (2004) Psychosocial factors at work and depression in three countries of Central and Eastern Europe. Soc Sci Med 58: 1475-1482.
40. Tsutsumi A, Kayaba K, Theorell T, Siegrist J (2001) Association between job stress and depression among Japanese employees threatened by job loss in a comparison between two complementary job-stress models. Scand J Work Environ Health 27: 146-153.

41. Siegrist J (1999) Occupational health and public health in Germany. In Le Blanc PM, Peeters MCW, Bussing A, Schaufeli WB, editors. Organizational Psychology and Healthcare: European Contributions. Munchen: Rainer Hampp Verlag 35-44.

42. Hanson EK, Schaufeli W, Vrijkotte T, Plomp NH, Godaert GL (2000) The validity and reliability of the Dutch Effort Reward Imbalance Questionnaire. J Occup Health Psychol 5: 142-55. 